\title{
Study on the License Mode of Value-Added Exploitation of Public Sector information
}

\author{
Haiying Hua, Shuren Zhu \\ Guangdong University of Finance and Econmomics, Guangzhou, 020-84096901, China \\ e-mail: hrice77@sina.com
}

\begin{abstract}
How to license PSI (public sector information) to those commercial reusers has become so urgent and important issue. The paper discussed the different license mode of value-added exploitation of Public Sector Information in UK and United States. Based on the investigation and comparison, the paper proposed some valuable suggestions on the construction of license mode of value-added exploitation of PSI in China: A clear attribution of property of public sector information and a clear range of Public sector information that can be accessed and be commercial reused and exploited; A diversification license based on clear classification of Public Sector Information; To establish unified management institute and supervisory body and so on.
\end{abstract}

Keywords: public sector information, license mode, government information

\section{Introduction}

Public sector information is the object of intellectual property, such as copyright, patent and so on. As a result, the first and most important things for the commercial exploitation of Public Sector information is how to access those information .However, abundant public sector information can be attributed to different property rules. even if some public sector information can not become the object of intellectual property, it doesn't mean that every one can freely access and reuse those information ,because those public sector information isn't equal to those information in public domain. for example, some information is limited to be accessed ,reused and dissemination required by some regulation such as Security Act. So it is necessary to know the clear attribution of property of PSI in order to get the license which can specify how to access ,reuse and disseminate those information .but how to finished and construct a just, fair ,non-discrimination and transparent license mode will be the important step for the thrive of digital content industry based-on those PSI. The paper will highlight those different license mode on the value-added exploitation of public sector information and propose some valuable suggestions on the construction of license mode in China. Certainly, not all exploitation of public sector information have to get the license before commercial reused, which is not covered in the paper here [1-4].

The license mode here is means that how to license Pubic sector information to be reused and commercial exploited, how to charge on the access of PSI as well as the specific progress and types of license, which is really the balance process of interests between those public sector, company that wants to reuse those information and the public .here ,the paper will discuss those operational problems of license based on the research of the mechanism in American as well as European countries especially United Kindom [5-7].

The paper are divided into three parts :the fist part discusses the click-use license and UK government Licensing framework; the second part highlight the license framework of United State local government. finally, some valuable suggestions on the construction of license mode in China is proposed on the above analysis and comparison.

\section{Research Method and Result}

The papaer has reviewed the framework in UK and United States. Those information are gathered form those relating websites, some regulations and laws.moreover, some reusers have been interviewed during the period .from those inforamtion ,the author describe the diffrent framwork license mode of PSI . 
In UK, there are two parallel modes of license PSI. It means that PSIHs (Public Sector Information Holders) supply their information for re-use through two routes. The one is common and the vast majority of PSIHs use the Click-Use License system to dealing issues of license, which is run by OPSI (office of public sector information) on line. This allows PSIHs to leave the practical administration of licensing their information to OPSI. The simple online system provides third parties with a license entitling them to re-use 'core Crown copyright information', 'Parliamentary copyright information' and 'value-added Crown copyright information'. The other route is that PSIHs license information directly to re-user, for example, the Met Office and the Driving Standards Agency. Of course, their licensing activity will be managed by the Controller of HMSO and the Information Fair Trader Schem (simplified into IFTS), operated by OPSI. However, these license mode has been changed into open government license, which is the result of movements of Creative commons. We will discussed the topic following here.

In UK, the license mode is the click-Use license on line of OPSI. It means that the vast majority of PSIHs depend on the Click-Use License system run by OPSI. This allows PSIHs to leave the practical administration of licensing their information to OPSI. OPSI create a website, where every value-added enterprises can find ,search even sign those click-use licenses, which have been authorized firstly by those PSIHS. The online system provides third parties with a license entitling them to re-use 'core Crown copyright information', 'Parliamentary copyright information' and 'value-added Crown copyright information'. as a result, three licenses have been created:PSI license(which is called Core license also),value added license and Parliamentary license. (see also table 1) the only difference between those license is the type of $\mathrm{PSI}$ and the different charges.

Table 1. Types of click-use license

\begin{tabular}{|c|c|c|}
\hline Type & Applied PSI & Charge \\
\hline PSI License & Also called Core License, which is applied all PSI information & free \\
\hline Value Added License & Allied all valued added royal copyright information & $\begin{array}{l}\text { Charge on } \\
\text { Marginal cost }\end{array}$ \\
\hline Parliamentary License & Applied all parliamentary copyright information & free \\
\hline
\end{tabular}

From the table, we can see that different type of those licenses have different terms and fees on the reuse of PSI. For an instance, the Value Added License is charged on marginal cost ,which is exactly the reflection of the regulation that is required in" How to Charge on Information" that raw information can charge on marginal cost and value-added information on market price or cost-recovery.

However, the pattern has been replaced by the open government license pattern, which is the result of Creative common Movement. Moreover, OPSI have incorporated into British archive Bureau, a new UK government licensing framework is issued in 2010. Under the new framework, there are two license ,one is the open government license, which is applied for any free users and value-added users of government information no matter for profit or not for-profit; but there are some public sector information can only be reused or exploited under the condition that is not for profit, so the non-profit license has been created.

The framework follows the following principles, firstly it is simple; it means not only the terms and conditions are easily understood but also the process for license.secondly,the agreement is non-exclusive agreement it is fair and equal for all the reusers of PSI and access those information fairly. Thirdly, the license conditions must be fair and non-discrimination. finally ,all the commpanies have to respect the right of authorship of PSIHs and be proviede in the wide and easily used way. moreover, Under the framework those data can be used interchange with the data under Creative commons And open access data with machine-readable metadata, which is very important for the network interoperability.

Besides.there have the negotiation pattern in UK. Some PSHs publish, manage licensing matters of PSI themselves, not by OPSI or National archives Bureau. This result those company have to get in touch with the Public sector and negotiate with them on the terms, conditions and prices of license. In order to supervise those PSIhs. all terms and conditions of license have to be monitored by IFTS,. Once the results isn't abide by, then OPSI will interfere 
and establish dispute complaint mechanism to examine and verify those possible wrongly license agreement.

All the above ensure a just, fair and transparent conditions for the reuse and commercial exploitation of PSI, Which will thrive the information industry and digital content industry in the end.

Great different access policy on PSI has result different license pattern from European Countries and United states .Federal government information can be freely accessed, used or reused no matter your purposes under the American copyright and Freedom of information Act. So, users don't have to get licenses and pay for the fees for access PSI at all except as required by law. for example some information created by contracting our and Franchise.

However, the local government information is free from those above Acts, especially Freedom of Information Act. So local governments have created their suitable license patterns. For example that the Information Society of Kentucky Louisville and Jefferson Country licensed their abundant data on real estate, road, roadside fire, hydrant building address to private company to commercial exploited, Information System of underground railway geographic in Minneapolis/M Sao Paulo has been accessed at a price per hours early in the nineties of 20th century. Moreover, custom geographic information service is also provided [1].

However, all the above license confined to the third party's reuse. re-dissemination and creation of new derived production on the public sector information. The license fee weren't free but on marginal cost or market price of return on investment.

Comparing those above two patterns. The first one has some more advantages for the situation of our country, not only the process but the matching law situation. From the license pattern of European Countries ,we can conclude those following trends that: a clear trend is that the license process is more simplified. We can easily get that information from the fact that UK has change into open government license patter. which greatly benefit and decrease the transaction in access those public sector information.

License is issued and managed completely automation and digitalization. moreover, the open government license pattern has a certain machine readability and related ontology metadata description, which contribute to the interoperability among different systems ,to improve the efficiency on the commercial reuse of PSI. Standard and general license is more and more common and convenient. now, a standard and general license called open government license take place those different online licenses depending on different types of PSI.

All the license are supervised and evaluated under the non-profit organization . In UK, it is OPSI and National archive Bureau. however, Public sector information have their own choice to decide if license public sector information to be commercial exploited or reused. So, we can learn a lot form European countries especially the United Kindom license pattern. the following are our conclusions.

\section{Conclusion}

In order to thrive the industy based on PSI in China, we think that it is necessary to have a clear attribution of property of public sector information and a clear range of Public sector information that can be accessed and be commercial reused and exploited. It is the first step to have a clear attribution of property of PSI .however, PSI have diversified character, so it is a real hard task to attribute a clear and legal property.

From the right point of view, The right maybe copyright, neighboring right, patent etc. sometime even some particular property, required by some particular law. For example, water conservancy science data, can't be protected under copyright, but can be protected under "water conservancy science data sharing management detailed rules for the implementation of the measures", which specify that users can't transfer water scientific data from sharing center [2]. So ,those water scientific data is protected by Secret Act in China. looking at in another way, it means that some PSI even are not the object of copyright, but PSIHs can also control their use, dissemination and commercial exploitation by some other law. The confusion in property greatly hinder the commercial reuse of PSI in the end .so it is urgent to have a clear attribution of property of public sector information and range of public sector information.

As for the range, we can learn a lot from those practices from United Kindom and some European Countries. The European Directive on reuse of PSI has clear defined how and what 
type of PSI can be reused and commercial exploited, which will provide reference value for our government on the relating issues.

Secondly, it is also important to have a diversification license based on clear classification of Public Sector Information.Based on practices in Chinese and European Countries, we should classify Public sector information into basic PSI and value-added PSI. Different types of different PSI will be applied different license based on our commercial reuse of PSI practices. As to those basic PSI License, however, we can also reference on the above practice of open government license with non-exclusive agreement, reservation right of authorship. all of this will simplify the process of access those PSI the above practice also show up in the geographic data license in American[3] as well as in UK. [4]

Finally, it is necessary to establish a unified management institute and supervisory body. The unified management institute and supervisory body here must be established under national management organization such as National Archive. At the same time, the function of the organization includes creating one-stop website, where can easily finished all the license. Secondly, the organization have to exercise supervision duties and be responsible for complaint affairs. For example, some resolutions on disputes relating the commercial reuse of PSI. investigations, assessment reports on PSIHs and so on.

\section{References}

[1] Huangxuan. Research on the mechinsm on value-added exploitation of government information. wuhan : wuhan University, $2008: 84$.

[2] http://www.sanstart.com/swglf/swglf/docinfo/DocInfoAction/showOne.show?docld=21. M.A. Green: High Efficiency Silicon Solar Cells (Trans Tech Publications, Switzerland 1987).

[3] Board on Earth Sciences and Resources. Licensing Geographic Data and Services. Washington, D.C:The National Academies Press, 2004:256-259.

[4] European Parliament, European Council. Directive 2003/98/EC of the European Parliament and of the Council of 17 November 2003 on the reuse of public sector information. Official Journal of the European Union. 2003; (345): 90-96.

[5] RJ Ong, JT Dawley and PG Clem. submitted to Journal of Materials Research. 2003.

[6] PG Clem, M Rodriguez, JA Voigt and CS Ashley. U.S. Patent 6,231,666. 2001.

[7] OPSI. Crown Copyright - an overview for government departments[EB/OL].[2011-03-04]. http://www.opsi.gov.uk/advice/crown-copyright/copyright-guidance/crown-copyright-an-overview-forgovernment-departments.htm. 